\title{
Protection from Half-mustard-gas-induced Acute Lung Injury in the Rat
}

\author{
Shannon D. McClintock, ${ }^{1}$ Gerd O. Till, ${ }^{1 *}$ Milton G. Smith ${ }^{2}$ and Peter A. Ward ${ }^{1}$ \\ ${ }^{1}$ Department of Pathology, University of Michigan Medical School, Ann Arbor, MI 48109-0602, USA \\ 2 Amaox Ltd, Silver Springs, MD, USA
}

\begin{abstract}
Key words: Half-mustard gas; lung injury; complement; neutrophils; antioxidants; $N$-acetyl-L-cysteine.
The chemical warfare agent analog, 2-chloroethyl ethyl sulfide, known as 'half-mustard gas' (HMG), is less toxic and less of an environmental hazard than the full molecule and has been shown to produce an acute lung injury in rats when instilled via intrapulmonary injection. This injury is characterized by massive, localized hemorrhage and edema into the alveolar compartment and can be quantitated by measuring extravasation of ${ }^{125}$ I-bovine serum albumin into the extravascular compartment. Employing this rat model of HMG-induced lung injury, we observed significant attenuation of the pulmonary injury when experimental animals were complement or neutrophil depleted prior to HMG challenge. Significant protection also was provided by the use of antioxidants such as catalase, dimethyl sulfoxide, dimethyl thiourea, resveratrol and $N$-acetylL-cysteine (NAC). The last compound showed protection from lung injury as high as $70 \%$ and was still effective even when given up to $90 \mathrm{~min}$ after exposure of the lungs to HMG. These data suggest that acute lung injury caused by exposure to HMG may be related partially to complement mediated pathways and the generation by neutrophils of toxic oxygen species The data indicate that NAC is an effective antidote against HMG-induced acute lung injury in the rat. Copyright $\subset 2002$ John Wiley \& Sons, Ltd.
\end{abstract}

\section{INTRODUCTION}

Mustard gas [bis (2-chloroethyl) sulfide, also known as sulfur mustard (HD)] was first synthesized in the early to mid-1800s. ${ }^{1}$ It is an oily liquid and is a lipophilic alkylating agent that, when absorbed, causes chemical reactions with cellular components, resulting in cytotoxic effects. ${ }^{1-6}$ Mustard agents are most commonly described as vesicating or blistering agents, owing to the fact that the wounds most often seen in HD exposure resemble burns and blisters. Mustard agents can be described more accurately as vesicating and tissue-damaging agents because of the severe widespread damage to the lungs, ${ }^{7,8}$ internal organs ${ }^{9-12}$ and eyes, ${ }^{13}$ as well as to the skin. ${ }^{14,15}$ Mustard gas also has been described as radiomimetic, carcinogenic, teratogenic and mutagenic. ${ }^{16-19}$ It has been used recently in chemical attacks against the Iranians during the Gulf War of 1984-1985 and by the Iraqis in 1988 against their own Kurdish population. ${ }^{6,20}$ Unfortunately, there is no effective treatment for HD intoxication. Decontamination of HD immediately after contact is still the recommended treatment. ${ }^{1,6}$

In addition to skin, the lungs and respiratory tract are among the most commonly affected organs, with effects that can be both acute (owing to its vesicating action) and long term (including airway hyperreactivity,

* Correspondence to: Gerd O. Till, University of Michigan Medical School, Department of Pathology, 1301 Catherine Street, Box 0602, Ann Arbor, MI 48109-0602, USA. E-mail: gerd.till@umich.edu Contract/grant sponsor: US DoD/Meharry Medical College. chronic bronchitis, asthma, bronchiectasis and pulmonary fibrosis). ${ }^{17,18}$ Complications due to HD exposure also can include hemorrhagic inflammation, erosion and effects on the lung parenchyma. ${ }^{17,18,21-23}$ There has been only a limited number of animal studies investigating HD-induced lung injury. Calvet et al..$^{21-23}$ have described the development of peribronchial edema and bronchoconstriction in guinea pigs, whereas Vijayaraghavan et al. ${ }^{19,24}$ have studied the changes in breathing patterns caused by inhaled or percutaneous exposure to HD in mice and rats.

A rat lung injury model has been established in our laboratory to study the effectiveness of complement and neutrophil depletion as well as treatment with antioxidants in attenuating injury caused by intrapulmonary instillation of half-mustard gas (HMG). Based on our long-standing experience with experimental pulmonary injury models in the rat, ${ }^{25-27}$ we have chosen this species to study the pathogenesis of HMG (2-chloroethyl ethyl sulfide)induced acute lung injury. Half-mustard gas is the standard agent employed for studies in order to avoid the need for high-level containment facilities.

\section{MATERIALS AND METHODS}

\section{Chemicals}

Except where noted, all chemicals and reagents were purchased from Sigma Chemical Co. (St. Louis, MO). 


\section{Animals}

Adult male (275-325 g) specific-pathogen-free LongEvans rats (Harlan Co., Indianapolis, IN) were used in these studies. Intraperitoneal ketamine $\left(100 \mathrm{mg} \mathrm{kg}^{-1}\right.$ body weight) (Fort Dodge Animal Health, Fort Dodge, IA) was used for continuous anesthesia and sedation (4 h). After induction of anesthesia, ${ }^{125}$ I-labeled bovine serum albumin ([ $\left.{ }^{125} \mathrm{I}\right] \mathrm{BSA}, 0.5 \mu \mathrm{Ci}$ per rat) was injected intravenously as a quantitative marker for vascular permeability. The trachea then was surgically exposed and a slightly curved catheter was inserted into the trachea past the bifurcation to facilitate a unilateral, left-lung injury. A small volume of HMG ( $2 \mu \mathrm{l}$ per rat) was solubilized in ethanol (58 $\mu \mathrm{l}$ per rat) and then added to a syringe containing Dulbecco's phosphate-buffered saline (DPBS) $(340 \mu \mathrm{l}$ per rat). This solution was injected via the intratracheal catheter, causing a unilateral lung injury. Studies not requiring the use of a radiolabeled marker proceeded identically, substituting DPBS for the radioactive injection. For all studies, except the time response experiment, animals were sacrificed $4 \mathrm{~h}$ later, the pulmonary circulation was flushed with $10 \mathrm{ml}$ of cold DPBS, the lungs were surgically dissected and placed in counting vessels and the amount of radioactivity ([ $\left.{ }^{125} \mathrm{I}\right] \mathrm{BSA}$ ) was determined by gamma counting. For calculations of the permeability index, the amount of radioactivity ([ $\left.{ }^{125} \mathrm{I}\right] \mathrm{BSA}$ ) remaining in the lungs in which the vasculature was perfused with saline was divided by the amount of radioactivity present in $1.0 \mathrm{ml}$ of blood obtained from the posterior vena cava at the time of sacrifice.

All animal experiments were in accordance with the standards in 'The Guide for the Care and Use of Laboratory Animals' and were supervised by veterinarians from the Unit for Laboratory and Animal Care of the University of Michigan Medical School.

\section{Neutrophil depletion}

Neutrophil depletion was induced by intraperitoneal injection of $1.0 \mathrm{ml}$ of rabbit anti-serum to rat polymorphonuclear neutrophils PMNs (Accurate, Westbury, NY). Twenty-four hours later, peripheral venous blood was obtained from the tail vein and analyzed for total neutrophil counts. The antibody reduced the number of neutrophils in peripheral blood by $>90 \% .^{25}$

\section{Complement depletion}

Cobra venom factor (CVF) was purified from crude, lyophilized cobra venom (Naja atra) by ion exchange chromatography. ${ }^{28}$ Complement depletion of experimental animals was achieved by intraperitoneal injections of 25 units of CVF per rat at time zero and $24 \mathrm{~h}$ later, resulting in undetectable levels of serum hemolytic complement activity as confirmed by $\mathrm{CH} 50$ assay. ${ }^{26}$ Experiments were performed $24 \mathrm{~h}$ after the second CVF injection.

\section{Antioxidants}

The dosing of the antioxidant compounds used in the present study has proved effective in other rat models of acute lung injury that were also dependent on blood neutrophils and complement. ${ }^{25,29,30}$ The following antioxidant compounds were tested separately and given intraperitoneally $10 \mathrm{~min}$ prior to intrapulmonary instillation of HMG: dimethyl thiourea (DMTU) (1000 mg kg-1 body wt. in $1.0 \mathrm{ml}$ of sterile DPBS), dimethyl sulfoxide (DMSO) $\left(1.5 \mathrm{ml} \mathrm{kg}^{-1}\right.$ body wt in $1.0 \mathrm{ml}$ of sterile DPBS); catalase (250000 units per rat in $2.0 \mathrm{ml}$ of sterile DPBS); and resveratrol (50 mg kg-1 body wt in $0.5 \mathrm{ml}$ of propylene glycol).

$N$-Acetyl-L-cysteine (NAC) was administered intravenously in varying concentrations and at different time points throughout the course of the HMG injury to establish both time and dose response data. The iron chelator-2,3-dihydroxybenzoic acid $\left(100 \mathrm{mg} \mathrm{kg}^{-1}\right.$ body wt in $0.5 \mathrm{ml}$ of DPBS) or deferoxamine mesylate $\left(15 \mathrm{mg} \mathrm{kg}^{-1}\right.$ body wt in $0.5 \mathrm{ml}$ of DPBS) - was injected intravenously 10 min prior to HMG instillation. As mentioned above, all chemicals were purchased from Sigma Chemical Co. (St. Louis, MO).

\section{Statistical analysis}

Results are presented as mean \pm SEM in the text and figures. Groups $(n=5)$ were subjected to one-way analysis of variance and when significance was found Student's $t$-test with the Bonferroni correction for multiple comparisons was applied. A value of $P<0.05$ was considered significant.

\section{RESULTS}

\section{Dose and time dependency of HMG- induced lung injury}

A lung injury model was developed in the rat using HMG in our laboratory (for details, see above). Extravasation of $\left[{ }^{125} \mathrm{I}\right] \mathrm{BSA}$ was used as a measure of tissue damage in the lung $4 \mathrm{~h}$ after HMG injection. A dose response experiment was run over a period of $4 \mathrm{~h}$. Animals treated included a group of controls and groups of animals treated intrapulmonary with $3,6,9$ or $12 \mathrm{mg} \mathrm{HGM} \mathrm{kg}^{-1}$ body wt. The results are shown in Fig. 1. The control group (intrapulmonary injection of the vehicle only) produced a background permeability value of $0.25 \pm 0.03$. Treatments with $3,6,9$ or $12 \mathrm{mg}$ of HMG yielded lung permeability indices of $0.97 \pm 0.17,1.92 \pm 0.17,2.00 \pm 0.31$ and $2.23 \pm 0.16$, respectively. From the dose response studies, the dosage of $6 \mathrm{mg} \mathrm{kg}^{-1}$ (about $2 \mathrm{mg}$ of HMG per rat) was selected. All the subsequent experiments used this concentration of HMG.

A time dependency experiment was run after determining the optimal dosage of HMG. When lung injury values were determined at 2, 4 and $6 \mathrm{~h}$ after $\mathrm{HMG}$ instillation into the lungs, injury values of $0.76 \pm 0.19,1.92 \pm 0.17$ and $4.08 \pm 0.19$, respectively, were obtained (Fig. 2). These studies indicated an almost linear increase in injury during the first $4 \mathrm{~h}$ of injury and confirmed the suitability of the 4-h time point for our studies. Unless otherwise noted, the 4-h time point following exposure to HMG was used, because previous studies with acute lung injury employed the same time point.

\section{Protective effects of neutrophil depletion}

Blood neutrophil depletion ( $<250$ neutrophils $\mu l^{-1}$ blood) was induced by the injection of a rabbit anti-rat PMN 


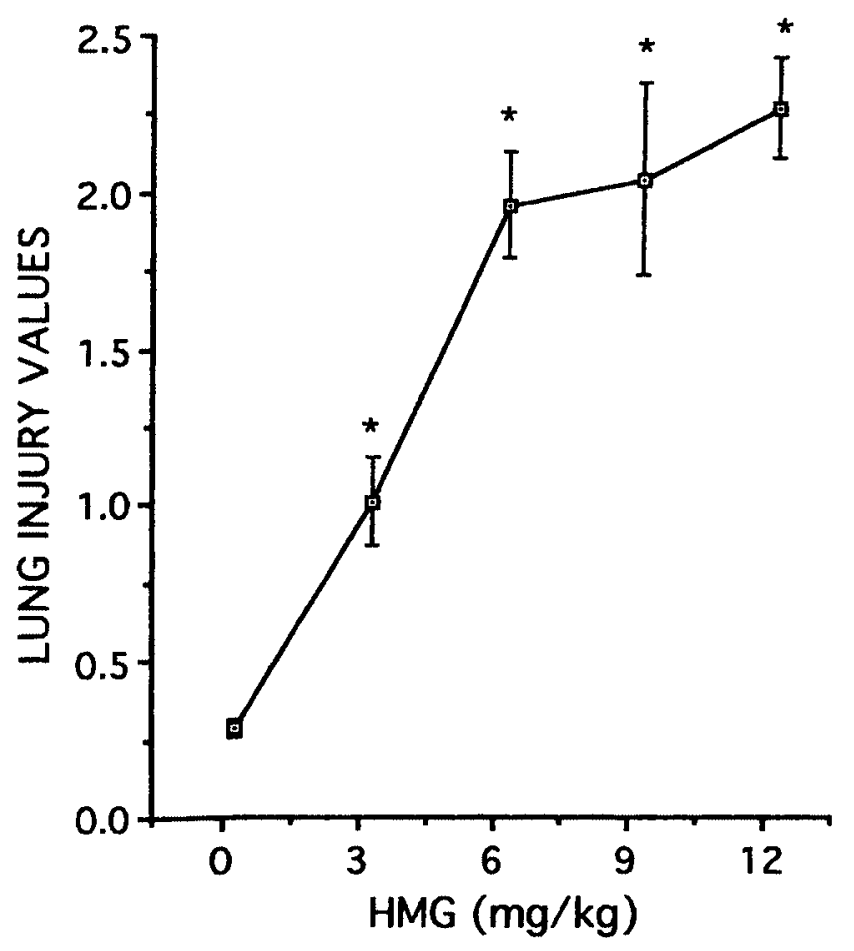

Figure 1. Dose-dependent increases in acute pulmonary injury (lung injury values defined by the permeability index) in the rat caused by HMG. Lung injury was determined at $4 \mathrm{~h}$ after intrapulmonary HMG injection. Based on these observations, $6 \mathrm{mg}$ HMG $\mathrm{kg}^{-1}$ body wt was chosen for all subsequent experiments. ${ }^{*}$ Significant changes compared with reference value and $n=5$ for each bar, for this and all subsequent figures.

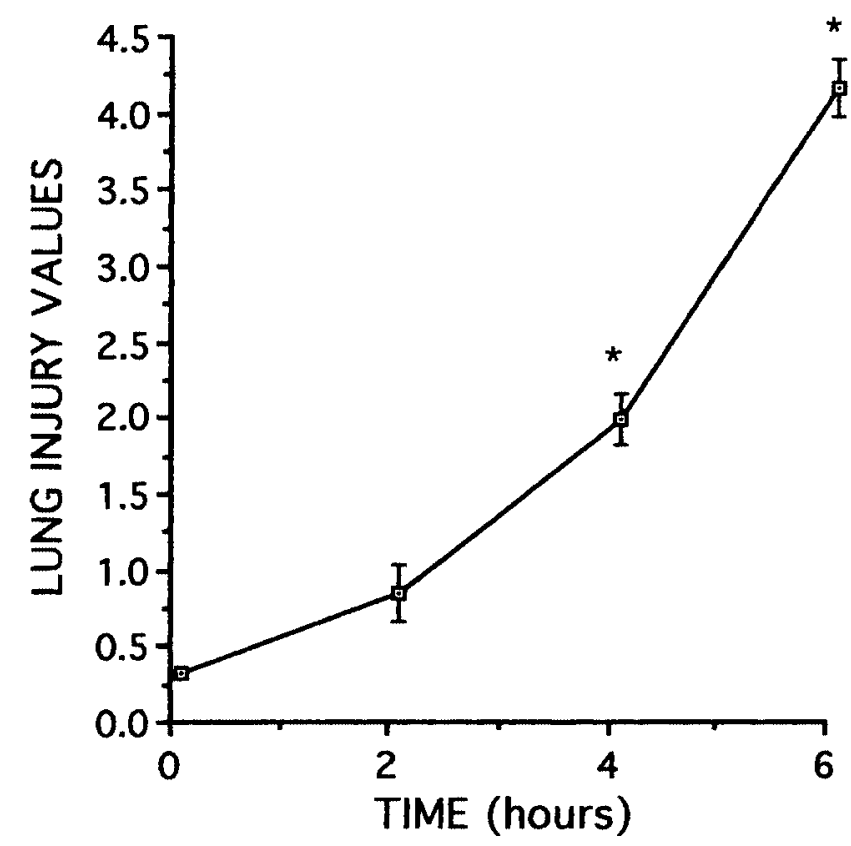

Figure 2. Time-dependent increases in lung injury values following intrapulmonary HMG $\left(6 \mathrm{mg} \mathrm{kg}^{-1}\right)$ injection into rats. Based on these observations, lung injury was determined in subsequent studies at $4 \mathrm{~h}$ post-HMG injection.

antibody as described above. ${ }^{125}$ I-Labeled BSA extravasation was used as a measure of tissue damage in the lung $4 \mathrm{~h}$ after the HMG instillation. Protection was calculated after subtracting the negative control values from the positive controls and lung injury values obtained from experimental animals. The results of neutrophil depletion on HMG-induced lung injury are shown in Fig. 3. As can be seen, neutrophil depletion was associated with a $62 \%$ reduction in HMG-induced lung injury (neutrophildepleted rats showed a mean permeability index of $0.88 \pm$ 0.07 , compared with a value of $1.92 \pm 0.17$ for nonneutropenic rats). This indicates that full development of the HMG-induced lung injury requires the availability of neutrophils.

\section{Protective effects of complement depletion}

Complement depletion was achieved by the serial intraperitoneal administration of CVF as described above. The results of complement depletion on vascular permeability are illustrated in Fig. 3. Depletion of complement resulted in a $43 \%$ reduction in lung injury (complement-depleted rats had a permeability index of $1.21 \pm 0.05$, compared with a value of $1.92 \pm 0.17$ for non-depleted rats). These observations indicate that full development of the HMG-induced lung injury is, at least in part, complement dependent.

\section{Protection by antioxidants}

The dosing of the antioxidant compounds used in the present study (see above) has proved effective in other rat models of acute lung injury that were also dependent on blood neutrophils and complement. ${ }^{25-27}$ The results of these interventional studies in the HMG model are depicted in Fig. 4. The DMSO treatment resulted in a $51 \%$ reduction of the observed positive control injury (DMSO administration showed a lung injury value of $1.07 \pm 0.013$, compared with a value of $1.92 \pm 0.17$ for non-treated rats). The DMTU afforded a $38 \%$ protective effect (mean lung injury value $=1.29 \pm 0.02$ ). Catalase treatment resulted in a $47 \%$ protective effect (lung injury value $=1.13 \pm 0.14$ ). Treatment with resveratrol-a phytoalexin and one of several antioxidants found in wine ${ }^{31,32}$ - resulted in a $61 \%$ reduction in HMGinduced lung injury (mean lung injury value $=0.91 \pm$ $0.03)$. The iron chelators 2,3 dihydroxybenzoic acid (DHBA) and deferoxamine mesylate (desferal) showed no significant protection.

In summary, significant reductions in lung injury were seen when catalase, the hydroxyl radical scavengers (DMSO and DMTU) and resveratrol were given. Superoxide dismutase (SOD), 2,3-dihydroxybenzoic acid (DHBA)

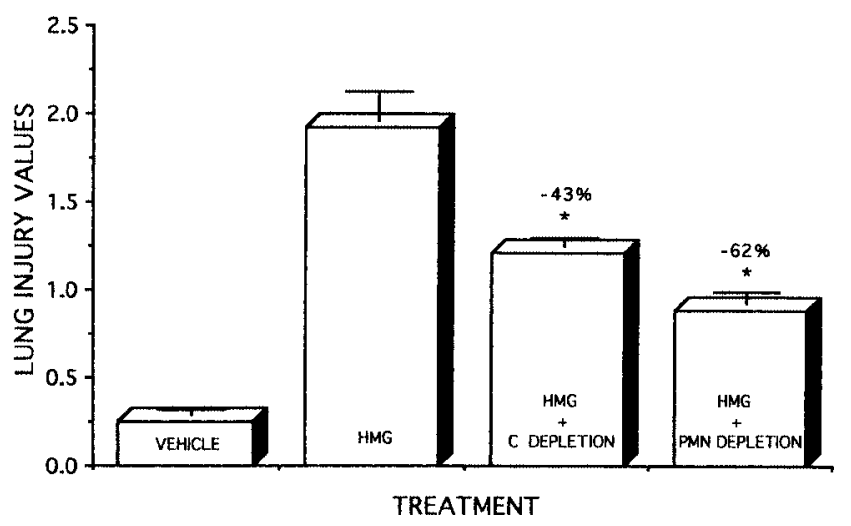

Figure 3. Intrapulmonary HMG injection into complement (C)depleted or neutrophil (PMN)-depleted rats. 


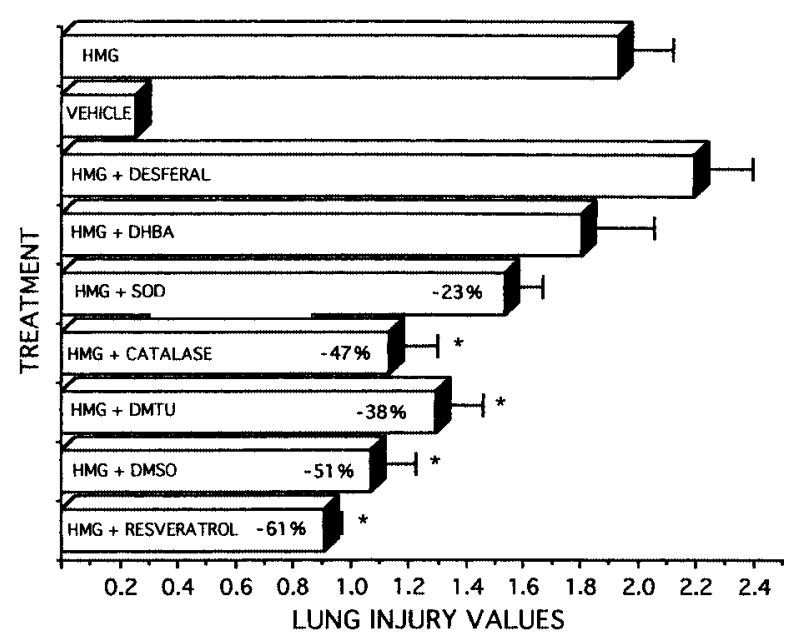

Figure 4. Effect of various antioxidants on HMG-induced acute lung injury. Test compounds included iron chelators, [desferal and 2,3-dihydroxybenzoic acid (DHBA)], antioxidant enzymes [catalase and superoxide dismutase (SOD)], hydroxyl radical scavengers [dimethyl thiourea (DMTU) and dimethyl sulfoxide (DMSO)] and a phytoalexin (resveratrol), which can also display antioxidative effects. For further details, see text.

and desferal showed no protective effects (Fig. 4). These observations support the concept of toxic oxygen species in the pathogenesis of HMG-induced acute lung injury.

\section{$N$-Acetyl-L-cysteine (NAC) dose responses and time dependency}

$N$-Acetyl-L-cysteine was also tested and demonstrated highly protective effects against HMG-induced lung injury (see data below). A dose response for intravenously administered NAC was generated for the 4-h HMG injury. All doses of NAC were given 10 min prior to instillation of the HMG. The NAC was used at doses of $5,10,20,30$ and $40 \mathrm{mg} \mathrm{kg}^{-1}$ body wt. The treatment groups at $4 \mathrm{~h}$ showed lung injury values of $1.53 \pm 0.06$ at $5 \mathrm{mg} \mathrm{kg}{ }^{-1}, 1.18 \pm 0.09$ at $10 \mathrm{mg} \mathrm{kg}^{-1}, 0.75 \pm 0.10$ at $20 \mathrm{mg} \mathrm{kg}^{-1}, 1.06 \pm 0.06$ at $30 \mathrm{mg} \mathrm{kg}^{-1}$ and $0.99 \pm 0.08$ at $40 \mathrm{mg} \mathrm{kg}^{-1}$ (Fig. 5). These data showed significant protection for all NAC doses tested, the highest being $70 \%$ for a NAC dose of $20 \mathrm{mg} \mathrm{kg}^{-1}$ (Fig. 5). From this experiment the optimum intravenous dosage of NAC was determined to be $20 \mathrm{mg} \mathrm{kg}^{-1}$ body wt.

The time course studies for the effectiveness of NAC treatments used the optimum dosing $\left(20 \mathrm{mg} \mathrm{kg}^{-1}\right.$ body wt i.v.) administered at various time points throughout the course of the injury. The treatment time points included the previously used $10 \mathrm{~min}$ prior to injury as well as administration of NAC 10, 30, 60, 90, 120 and $180 \mathrm{~min}$ after the instillation of HMG (Fig. 6). The 4-h lung injury values after $\mathrm{HMG}$ instillation were $1.23 \pm 0.02$ when NAC was given at $10 \mathrm{~min}, 0.99 \pm 0.02$ at $30 \mathrm{~min}$, $1.11 \pm 0.10$ at $60 \mathrm{~min}, 1.02 \pm 0.15$ at $90 \mathrm{~min}, 1.64 \pm$ 0.14 at $120 \mathrm{~min}$ and $2.04 \pm 0.30$ at $180 \mathrm{~min}$. These lung injury values translated into a $42 \%$ protection when NAC was given $10 \mathrm{~min}$ after $\mathrm{HMG}$ and rose to $56 \%$ and $49 \%$ protection for the 30 -min and 60 -min time points, respectively. Even when NAC treatment was administered as late as $90 \mathrm{~min}$ after HMG exposure, there was still a $54 \%$ reduction in lung injury. No significant changes were observed when NAC treatment was delayed by $>90 \mathrm{~min}$ (Fig. 6).

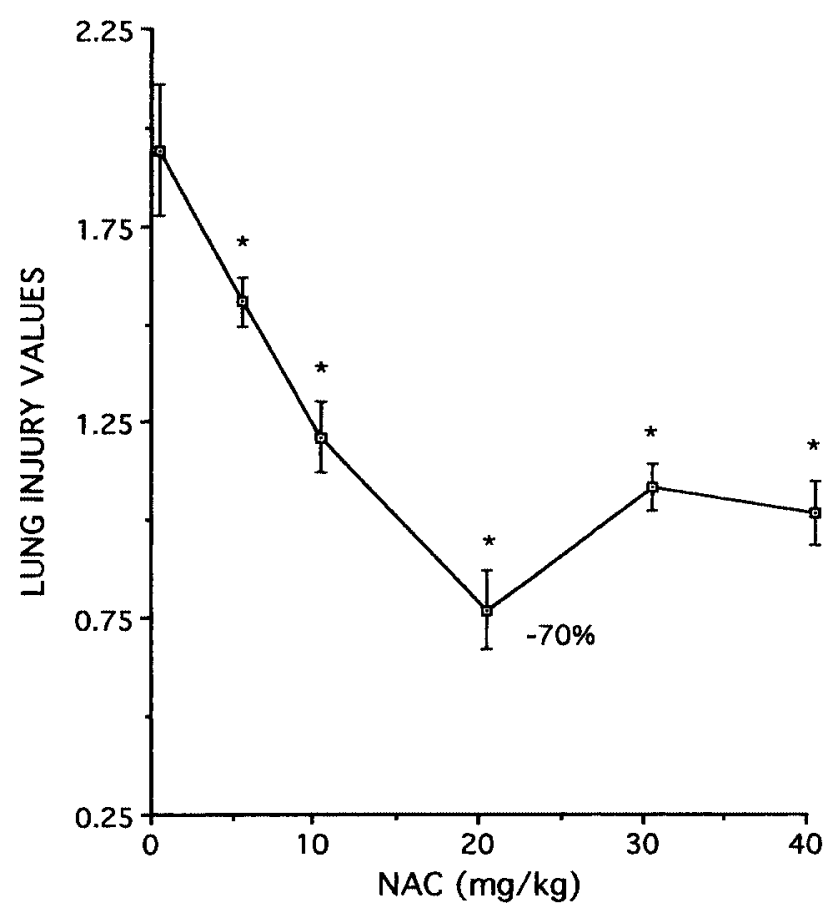

Figure 5. Dose-dependent protective effects of NAC on HMGinduced lung injury; NAC was injected $10 \mathrm{~min}$ prior to HMG. Lung injury values were determined at $4 \mathrm{~h}$ post-HMG injection.

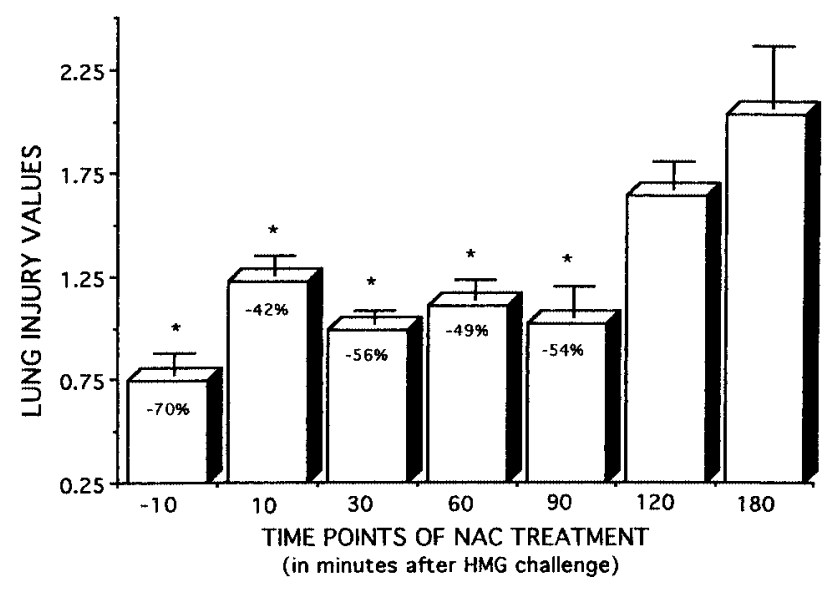

Figure 6. Effect of delayed NAC (20 mg kg $\left.{ }^{-1}\right)$ treatment of HMGinjected rats.

\section{DISCUSSION}

To elucidate the pathogenic mechanisms involved in the development of HM-induced lung injury and to assess promising therapeutic interventions, a new rat model of HMG-induced acute pulmonary injury has been developed. Employing this model, experimental data have been obtained that strongly suggest that the HMG-induced acute (4-h) lung injury requires a fully functioning complement system and the availability of blood neutrophils. Complement or neutrophil depletion of experimental animals prior to $\mathrm{HMG}$ challenge resulted in $40 \%$ and $60 \%$ protection from lung injury, respectively. These are new findings for this type of acute lung injury. Anderson et al. found increased numbers of neutrophils in bronchoalveolar lavage fluids of HD-treated rats. ${ }^{33}$ In 
chronic lung injury of patients exposed to mustard gas, neutrophilic alveolitis was described as a predominant feature. $^{34}$ The early appearance of neutrophils in HDinduced skin lesions is well established..$^{35}$ Although serum complement consumption by HD in vitro was reported in $1946,{ }^{36}$ and increased in vitro binding of Clq to HD-treated keratinocytes has been reported recently, ${ }^{37}$ the pathogenic role of complement in HD-induced organ injury remains a matter of speculation. It is assumed that complement activation products may participate in the pathogenesis of HMG-induced lung injury by stimulating neutrophils and other blood and organ cells.

Because other animal models of neutrophil- and complement-dependent acute lung injury have shown that, at least in part, toxic oxygen species are participating in the pathogenesis, ${ }^{25,29,38}$ the effect on HMG-induced lung injury of various antioxidants was investigated. As shown in Fig. 4, catalase, the hydroxyl radical scavengers (dimethyl thiourea and dimethyl sulfoxide) and the phytoalexin (resveratrol) all exhibited pronounced protection from HMG lung injury. Superoxide dismutase (SOD) reduced lung injury by $23 \%$, but these changes were not significant. Eldad et al. ${ }^{39}$ using a guinea pig model of HD-induced skin burns, saw significant reductions in the skin lesions when SOD was given intraperitoneally or intralesionally 1 or $3 \mathrm{~h}$ in advance of wound infliction. No protection was seen when SOD was given $1 \mathrm{~h}$ after skin exposure. We also tested iron chelators, which have shown strong protection in other models of oxidant-induced lung injury. ${ }^{30,40}$ Why desferal (deferoxamine) and 2,3-dihydroxybenzoic acid (DHBA) did not show any protective effect remains unclear at present. Nevertheless, oxidants appear to play a role in HMG-induced lung injury. Our observations are corroborated by a recently published study by Kumar et al., ${ }^{7}$ who demonstrated that antioxidants such as vitamin $\mathrm{E}$, quercetin and reduced glutathione (GSH) could enhance survival time and protect lungs from oxidative damage in mice exposed to HD.

Additional support for an involvement of oxidants in the pathogenesis of HMG-induced acute lung injury was provided by the dramatic effects seen after treatment of experimental animals with NAC. Not only did NAC demonstrate the most pronounced protection from lung injury (Fig. 5), but it also provided significant protection even when given as late as $90 \mathrm{~min}$ after intrapulmonary injection of HMG (Fig. 6). This protection after onset of the injury was not seen with any of the other antioxidants used in our study (data not shown). Others have observed decreased numbers of neutrophils in bronchoalveolar lavage fluids obtained from HD-injured lungs of rats that were treated intraperitoneally with NAC at the beginning of the experiment. ${ }^{41}$ The mechanisms of NACmediated protection from mustard-induced lung injury are not clear. Recent data by Atkins and colleagues ${ }^{42}$ seem to suggest that NAC protects from HD-induced apoptotic endothelial cell death by enhancing the synthesis of reduced glutathione, which in turn may scavenge HD and also prevent oxidative activation of the transcription factor NF-kappa-B, which is usually upregulated by stress signals.

In summary, our observations suggest that the development of HMG-induced lung injury is dependent on the availability of both neutrophils and complement, and is largely mediated by toxic oxygen metabolites. The latter is supported by our findings that NAC, a well-known antioxidant, has powerful protective effects related to the dose administered and the time of its administration.

\section{Acknowledgement}

Supported by a grant from the US DoD/Meharry Medical College.

\section{REFERENCES}

1. Reutter S. Hazards of chemical weapons release during war: new perspectives. Environ. Health Perspect. 1999; 107: 985-990.

2. Dacre JC, Goldman M. Toxicology and pharmacology of the warfare agent sulfur mustard. Pharmacol. Rev. 1996; 48: 289-296.

3. Lardot C, Dubois V, Lison D. Sulfur mustard upregulates the expression of interleukin-8 in cultured human keratinocytes. Toxicol. Lett. 1999; 110: 29-33.

4. Arroyo CM, Von Tersch RL, Broomfield CA. Activation of alpha-human tumour necrosis factor (TNF- $\alpha$ ) by human monocytes (THP-1) exposed to 2-chloroethyl ethyl sulphide (H-MG). Hum. Exp. Toxicol. 1995; 14: 547-553.

5. Sawyer TW, Hamilton MG. Effect of intracellular calcium modulation on sulfur mustard cytotoxicity in cultured human neonatal keratinocytes. Toxicol. In Vitro 2000; 14: 149-157.

6. Watson AP, Griffin GD. Toxicity of vesicant agents scheduled for destruction by the Chemical Stockpile Disposal Program. Environ. Health Perspect. 1992; 98: 259-280.

7. Kumar O, Sugendran K, Vijayaraghavan R. Protective effect of various antioxidants on the toxicity of sulphur mustard administered to mice by inhalation or percutaneous routes. Chem. Biol. Interact. 2001; 134: 1-12.
8. Lakshmana Rao PV, Vijayaraghavan R, Bhaskar ASB. Sulphur mustard induced DNA damage in mice after dermal and inhalational exposure. Toxicology 1999; 139: 39-51.

9. Maisonneuve A, Callebat I, Debordes L, Coppet L. Biological fate of sulphur mustard in rat: toxicokinetics and disposition. Xenobiotica 1993; 23: 771-780.

10. Maisonneuve A, Callebat I, Debordes L, Coppet L. Distribution of $\left[{ }^{14} \mathrm{C}\right]$ sulfur mustard in rats after intravenous exposure. Toxicol. Appl. Pharmacol 1994; 125: 281-287.

11. Mozier NM, Hoffman JL. Biosynthesis and urinary excretion of methyl sulfonium derivatives of the sulfur mustard analog, 2-chloroethyl ethyl sulfide, and other thioethers. FASEB J. 1990; 4: 3329-3333.

12. Tripathi DN, Suendran K, Malhotra RC, Bhattacharya A, Das Gupta S. Studies on urine and tissues of rats, guineapigs and mice to sulphur mustard using mass spectrometry. $J$. Biosci. 1995; 20: 29-33.

13. Varma SD, Devamanoharan PS, Ali AH, Brozetti J, Petrali J, Lehnert E, Weir A. Half mustard (CEES) induced damage to rabbit cornea: attenuating effect of taurine-pyruvate-alphaketoglutarate-pantothenate mixture. J. Ocul. Pharmacol. Ther. 1998; 14: 423-428.

14. Brown RFR, Rice P. Histopathological changes in Yucatan minipig skin following challenge with sulfur mustard. A sequential study of the first 24 hours following challenge. Int. J. Exp. Pathol. 1997; 78: 9-20. 
15. Eldad A, Ben Meir P, Breiterman S, Chaouat M, Shafran A, Ben-Bassat H. Superoxide dismutase (SOD) for mustard gas burns. Burns 1998; 24: 114-119.

16. Anguelov A, Belchen L, Angelov G. Experimental sulfur mustard gas poisoning and protective effect of different medicines in rats and rabbits. Indian Vet. J. 1996; 73: 546-551.

17. Emad A, Rezaian GR. Immunoglobulins and cellular constituents of the BAL fluid of patients with sulfur mustard gas-induced pulmonary fibrosis. Chest 1999; 115: $1346-1351$.

18. Emad A, Rezaian GR. Characteristics of bronchoalveolar lavage fluid in patients with sulfur mustard gas-induced asthma or chronic bronchitis. Am. J. Med. 1999; 106: 625-628.

19. Dube SN, Husain K, Sugendran K, Vijayaraghavan R, Somani SM. Dose response of sulphur mustard: behavioral and toxic signs in rats. Indian J. Physiol. Pharmacol. 1998; 42: 389-394.

20. Conley J, Hunter K, Lundy $P$, Hamilton M, Sawyer TW. Domestic swine model for the assessment of chemical warfare agent-anesthetic interactions: some effects of sulfur mustard. Mil. Med. 2000; 165: 573-578.

21. Calvet JH, Jarreau JH, Levame M, D'Ortho MP, Lorino $H$, Harf A, Macquin-Mavier I. Acute and chronic respiratory effects of sulfur mustard intoxication in guinea pig. J. Appl. Physiol. 1994; 76: 681-688.

22. Calvet JH, D'Ortho MP, Jarreau JH, Levame M, Harf A, Macquin-Mavier I. Glucocorticoids inhibit sulfur mustardinduced airway muscle hyperresponsiveness to substance P. J. Appl. Physiol. 1994; 77: 2325-2332.

23. Calvet JH, Planus $E$, Rouet $P$, Pezet $S$, Levame $M$, Lafuma $C$, Harf A, D'Ortho MP. Matrix metalloproteinase gelatinases in sulfur mustard-induced acute airway injury in guinea pigs. Am. J. Physiol. 1999; 276: L754-762.

24. Vijayaraghavan R. Modifications of breathing pattern induced by inhaled sulphur mustard in mice. Arch. Toxicol. 1997; 71: 157-164.

25. Till GO, Johnson KJ, Kunkel R, Ward PA. Intravascular activation of complement and acute lung injury. Dependency on neutrophils and toxic oxygen metabolites. J. Clin. Invest. 1982; 69: 1126-1135.

26. Mulligan MS, Till GO, Smith CW, Anderson DC, Miyasaka M, Tamatani T, Todd RF 3rd, Issekutz TB, Ward PA. Role of leukocyte adhesion molecules in lung and dermal vascular injury after thermal trauma of skin. Am. J. Pathol. 1994; 144: 1008-1015.

27. Shanley TP, Foreback JL, Remick DG, Ulich TR, Kunkel SL, Ward PA. Regulatory effects of interleukin-6 in immunoglobulin $\mathrm{G}$ immune-complex-induced lung injury. Am. J. Pathol. 1997; 151: 193-203.

28. Ballow M, Cochrane CG. Two Anti-complementary factors in cobra venom. Hemolysis of guinea pig erythrocytes by one of them. J. Immunol. 1969; 103: 944-952.
29. Till GO, Beauchamp C, Menapace D, Tourtellotte W Jr, Kunkel R, Johnson KJ, Ward PA. Oxygen radical dependent lung damage following thermal injury of rat skin. J. Trauma 1983; 23: 269-277.

30. Ward PA, Till GO, Kunkel R, Beauchamp C. Evidence for role of hydroxyl radical in complement and neutrophildependent tissue injury. J. Clin. Invest. 1983; 72: 789-801.

31. Frankel EN, Waterhouse AL, Kinsella JE. Inhibition of human LDL oxidation by resveratrol. Lancet 1993; 341: 1103-1104.

32. Stojanovic S, Sprinz H, Brede O. Efficiency and mechanism of the antioxidant action of trans-resveratrol and its analogues in the radical liposome oxidation. Arch. Biochem. Biophys. 2001; 391: 79-89.

33. Anderson DR, Byers SL, Vesely KR. Treatment of sulfur mustard (HD)-induced lung injury. J. Appl. Toxicol. 2000; 21: S129-S132.

34. Emad A, Rezaian GR. Immunoglobulins and cellular constituents of the BAL fluid of patients with sulfur mustard gas-induced pulmonary fibrosis. Chest 1999; 115: 1346-1351.

35. Dannenberg AM, Pula PJ, Liu LH, Harada S, Tanaka F, Vogt RF, Kajiki A, Higuchi K. Inflammatory mediators and modulators released in organ culture from rabbit skin lesions produced in vivo by sulfur mustard. Am. J. Pathol. 1985; 121: $15-27$.

36. Boursnell JC, Francis GE, Wormall A. Studies on mustard gas (beta-beta'-dichlorodiethyl sulfide) and some related compounds. 8 . The action of mustard gas, divinyl sulphone and beta-beta-dichlorodiethyl sulphone on complement. Biochem. J. 1946; 40: 774-778.

37. Cowan FM, Broomfield CA, Smith WJ. Exposure of human epidermal keratinocyte cell cultures to sulfur mustard promotes binding of complement $\mathrm{C} 1 \mathrm{q}$ : implications for toxicity and medical countermeasures. J. Appl. Toxicol. 2000; 20: S77-S80.

38. Johnson KJ, Ward PA. Role of oxygen metabolites in immune complex injury of lungs. J. Immunol. 1981; 103: 2365-2369.

39. Eldad A, Ben Meir P, Breiterman S, Chaouat M, Shafran A, Ben-Bassat H. Superoxide dismutase (SOD) for mustard gas burns. Burns 1998; 24: 114-119.

40. Baldwin SR, Simon RH, Boxer LA, Till GO, Kunkel RG. Attenuation by 2,3-dihydroxybenzoic acid of acute lung injury induced by cobra venom factor in the rat. Am. Rev. Respir. Dis. 1985; 132: 1288-1293.

41. Anderson DR, Byers SL, Vesely KR. Treatment of sulfur mustard (HD)-induced lung injury. J. Appl. Toxicol. 2000; 20: S129-S132.

42. Atkins KB, Lodhi IJ, Hurley LL, Hinshaw DB. Nacetylcysteine and endothelial cell injury by sulfur mustard. J. Appl. Toxicol. 2000; 20: S125-S128. 